\title{
Phytochemical comparison and evaluation of anti-inflammatory and anti-diabetic activity of three source plants of Jivanti-an important Ayurvedic drug
}

\author{
Sulaiman C. T., Jyothi C. K., Jinu Krishnan Unnithan G., Prabhukumar K. M. and Indira Balachandran
}

\begin{abstract}
Background: In Ayurveda, Jivanti is an important Rasayana drug that increases the energy level of the body. The botanical source of Jivanti is in a situation of controversy. The root of Leptadenia reticulata is the genuine source plant for Jivanti as per Ayurvedic Pharmacopeia of India. However, other species such as Holostemma ada-kodien and Flickingeria nodosa are also used as source plants for Jivanti in various parts of the country. The objective of this study is to identify a scientifically validated alternative source plant for Jivanti by phytochemical and pharmacological evaluation.

Results: In this study, anti-inflammatory and anti-diabetic activities of various source plants for Jivanti were evaluated along with their phytochemical comparison. H. ada-kodien showed significant anti-inflammatory and antidiabetic activity when compared to $L$. reticulata.

Conclusion: The study concluded the possibility of using Holostemma ada-kodien as a substitute for Jivanti in the Ayurvedic drug industry.
\end{abstract}

Keywords: Jivanti, HPTLC, LC/MS, Anti-diabetic activity, Anti-inflammatory activity

\section{Background}

In Ayurveda, Jivanti is an important rejuvenating drug that boosts the energy level of the body [1]. The botanical identity of Jivanti is in a situation of controversy. Identification of an Ayurvedic drug from classical texts is difficult through etymological analysis of its terminology as it does not disclose identity. Identity needs detailed morphological descriptions in the literature and such descriptions in classical texts are unclear. The root of Leptadenia reticulata (Retz.) Wight \& Arn. (Apocynaceae) is accepted as the genuine source of Jivanti as per Ayurvedic Pharmacopeia of India, but various herbs are used under the name of Jivanti in different parts of the country. Holostemma ada-kodien (Apocynaceae) and

\footnotetext{
*Correspondence: sulaimanct@aryavaidyasala.com; sImnct@gmail.com Phytochemistry Division, Centre for Medicinal Plants Research, Arya Vaidya Sala, Kottakkal, Malappuram, Kerala 676503, India
}

Flickingeria nodosa (Orchidaceae) are the commonly used species as source plants for Jivanti. In the central and western part of India, $L$. reticulata is generally used as Jivanti, but in some regions, Flickingeria nodosa is also considered as a type of Jivanti which is commonly known as Suvarna Jivanti. In the southern part of India, Holostemma ada-kodien is considered as a source plant for Jivanti [2-5].

L. reticulata is a twining shrub that grows in subHimalayan tracts of Punjab, Gujarat, Uttar Pradesh, and throughout peninsular India [6]. L. reticulata is used for treating various ailments such as hematopoiesis, emaciation, cough, dyspnea, fever, burning sensation, night blindness, and dysentery [2]. H. ada-kodien, a species indigenous to India, is a twiny, laticiferous perennial medicinal shrub that is endangered. The tuberous root, which is the official part, is used for diabetes [7]. F. 
nodosa belonging to the family Orchidaceae is known as Suvarna Jivanti due to its golden yellow color [8]. The aim of the study is to compare the selected source plants for Jivanti by evaluating their phytochemical and pharmacological properties.

\section{Methods}

\section{Collection of plant materials}

Various plant materials were collected during September 2016. H. ada-kodien was collected from the nursery of the Centre. Dried roots and stems of L. reticulata were obtained from Dabur India Ltd, New Delhi. Flickingeria nodosa was obtained from Khari Baoli market, New Delhi. All the materials were authenticated by the Plant Systematics and Genetic Resources Division of the Centre and voucher specimens were deposited in the herbarium (CMPR 9684, CMPR 9685, and CMPR 9998).

\section{Extraction of materials}

Five grams each of the shade dried materials of L. reticulata root (LRR), L. reticulata stem (LRS), $H$. ada-kodien root (HAR), and F. nodosa whole plant (FNW) were successively extracted with various solvents like petroleum ether, chloroform, and methanol using reflux extraction method. Crude extracts with methanol, water, and hydro alcohol were also prepared separately by reflux extraction method.

One hundred fifty grams of each sample was individually extracted in water for pharmacological evaluation using the Soxhlet extraction method. The extracts were dried under vacuum by a rotary evaporator (Heidolph, Germany). All the extracts were stored under a refrigerator until phytochemical and pharmacological evaluation.

\section{Estimation of total polyphenolics}

Total phenolic content (TPC) was estimated spectrophotometrically $[9,10]$ and was expressed as mg gallic acid equivalents ( $\mathrm{mg} \mathrm{GaE}$ ).

\section{Extraction of phenolics}

Phenolic extraction was done by the previously reported method [11] with slight modification. Briefly, $10 \mathrm{~g}$ of materials was extracted with $100 \mathrm{ml}$ of $80 \%$ of ethanol at room temperature for $5 \mathrm{~h}$ using an incubator shaker. It was filtered and concentrated under vacuum at $40{ }^{\circ} \mathrm{C}$ using rotary evaporator (Heidolph, Germany). The $\mathrm{pH}$ was adjusted to 11 by adding sodium hydroxide. It was then extracted with $\mathrm{CHCl}_{3}$ to remove the chloroform soluble fraction. The residue was acidified with hydrochloric acid to $\mathrm{pH} 2$ and was extracted with $150 \mathrm{ml}$ of ethyl acetate. The ethyl acetate extract was concentrated and hydrolyzed with $50 \mathrm{ml}$ of $4 \mathrm{~N} \mathrm{NaOH}$, stirred at 50 ${ }^{\circ} \mathrm{C}$ for $5 \mathrm{~h}$ and $\mathrm{pH}$ was adjusted to 2 by adding hydrochloric acid. It was then extracted with ethyl acetate, concentrated to dryness, and it was dissolved in LC/MS grade methanol.

\section{High-performance thin-layer chromatographic (HPTLC) analysis}

Various extracts of $L$. reticulata, $H$. ada-kodien, and $F$. nodosa were subjected to chemical profiling by Camag HPTLC system (Switzerland). Samples were applied using an auto sampler (Camag ATS 4) on HPTLC plates $\left(60 \mathrm{~F}_{254}\right.$, Merck India). The mobile phase was optimized as toluene, ethyl acetate, and methanol in the ratio of 7: 2:1 for n-hexane and chloroform extracts and in the ratio of 7:3:1 for alcoholic and aqueous extracts. The chromatogram was developed in a saturated Twin Trough chromatographic chamber (Camag, Switzerland). The developed plate was visualized under UV at $254 \mathrm{~nm}$ and $366 \mathrm{~nm}$ and in visible light after derivatizing with anisaldehyde sulfuric acid reagent followed by heating at 105 ${ }^{\circ} \mathrm{C}$ for 5 min [12].

\section{LC-ESI/MS-MS analysis}

Mass spectroscopic characterization was done by electrospray ionization (ESI) technique in negative mode using Agilent 6520 accurate mass Q-TOF-LC/MS system with Agilent 1200 liquid chromatography having an extend-C18 column of $1.8 \mu \mathrm{m}, 2.1 \times 50 \mathrm{~mm}$. Gradient elution was performed with LC/MS grade acetonitrile (A) and $0.1 \%$ acetic acid in methanol (B) at a constant flow rate of $0.7 \mathrm{ml} / \mathrm{min}$, with an increase in the volume of $\mathrm{B} \%: 5-20 \%, 12-30 \%, 19-40 \%, 26-50 \%$, and $30-40 \%$. The conditions for mass spectrometry were drying gas (nitrogen) flow $5 \mathrm{l} / \mathrm{min}$, nebulizer pressure $40 \mathrm{psig}$, drying gas temperature $325{ }^{\circ} \mathrm{C}$, capillary voltage $3000 \mathrm{~V}$, and fragmentor volt $125 \mathrm{~V}$. The mass fragmentation was performed by collision-induced dissociation with varying collision energy $4 \mathrm{~V} / 100 \mathrm{DA}$ with an offset of $8 \mathrm{~V}$ [12].

\section{Anti-inflammatory activity Induction of paw edema using carrageenan}

Anti-inflammatory activity was evaluated using the carrageenan-induced rat paw edema model [13]. The study was approved by Institutional Animal Ethical Committee (IAEC) constituted for the purpose of CPCSEA, Government of India (Approval No: KAHE/IAEC/2018/ 21-04/009). The rats were challenged by subcutaneous injection of $0.05 \mathrm{ml}$ of $1 \%$ solution of carrageenan into the plantar side of the left hind paw after $30 \mathrm{~min}$ of $5 \mathrm{ml}$ of water (controls) by stomach tube or the test drug dissolved in the same volume of water.

\section{Experimental setup}

Male Sprague-Dawley rats with the body weight between 150 and $180 \mathrm{~g}$ were used. The animals were 
Table 1 Experimental design for anti-inflammatory activity

\begin{tabular}{lll}
\hline S.No & Groups & Experiment design \\
\hline 1 & Group I (control) & Water $5 \mathrm{ml}$ (each rat) \\
2 & Group II (induction) & Induction of $0.05 \mathrm{ml}$ of carrageenan \\
3 & Group III (FNW) & Treated with $5 \mathrm{ml}$ of FNW extract and after 30 min induced with $0.05 \mathrm{ml}$ of $1 \%$ carrageenan \\
4 & Group IV (LRR) & Treated with $5 \mathrm{ml}$ of LRR extract and after 30 min induced with $0.05 \mathrm{ml}$ of $1 \%$ carrageenan \\
5 & Group V (LRS) & Treated with $5 \mathrm{ml}$ of LRS extract and after 30 min induced with $0.05 \mathrm{ml} \mathrm{of} 1 \%$ carrageenan \\
6 & Group VI (HAR) & Treated with $5 \mathrm{ml}$ of HAR extract and after 30 min induced with $0.05 \mathrm{ml}$ of $1 \%$ carrageenan \\
\hline
\end{tabular}

divided into six groups of 4 rats in each group and starved overnight (Table 1).

The paw volume was measured using a vernier caliper immediately after injection and $30 \mathrm{~min}, 1 \mathrm{~h}, 2 \mathrm{~h}, 3 \mathrm{~h}, 4 \mathrm{~h}$, $5 \mathrm{~h}$, and $6 \mathrm{~h}$ after injection. The increase of paw volume after 3 to $6 \mathrm{~h}$ is calculated as percentage compared with the volume measured immediately after injection of the irritant for each animal.

\section{Evaluation of anti-diabetic activity by streptozotocin- induced diabetes \\ Animals and diet}

Adult Wistar albino rats weighing about 150-180 g were procured from the animal house of Karpagam Academy of Higher Education, Coimbatore, India. The animals were under standard conditions and were housed four per cage in polypropylene cages with a wire mesh top and a hygienic bed of husk in a specific pathogen-free animal room under controlled conditions of 12-h light and 12-h dark cycle, with a temperature of $24 \pm 2{ }^{\circ} \mathrm{C}$, relative humidity of $50 \pm$ $10 \%$, and fed with rodent diet and water ad libitum (Table 2). The study was approved by Institutional Animal Ethical Committee (IAEC) constituted for the purpose of CPCSEA, Government of India, with approval no. KAHE/IAEC/2018/21-04/008 [14].

\section{Induction of diabetes}

Rats were rendered diabetic by a single intraperitoneal injection of freshly prepared streptozotocin $(45 \mathrm{mg} / \mathrm{kg}$

Table 2 Experimental design for in vivo anti-diabetic study

\begin{tabular}{ll}
\hline Groups & Treatment \\
\hline Group 1 & Control \\
Group 2 & Diabetic control (streptozotocin $45 \mathrm{mg} / \mathrm{kg}$ b.wt) \\
Group 3 & Diabetic rats treated with glibenclamide (2 mg/kg b.wt) \\
Group 4 & Diabetic rats treated with FNW \\
Group 5 & Diabetic rats treated with LRR \\
Group 6 & Diabetic rats treated with LRS \\
Group 7 & Diabetic rats treated with HAR \\
\hline
\end{tabular}

b.wt) in $0.1 \mathrm{M}$ citrate buffer (pH 4.5) [14]. Diabetes was identified in rats by moderate polydipsia and marked polyuria. After $48 \mathrm{~h}$ of streptozotocin administration, blood glucose levels were estimated in rats following overnight fasting. Rats with a blood glucose ranging between 200 and $400 \mathrm{mg} / \mathrm{dl}$ were considered diabetic and used for the experiments.

The animals were weighed and dosed through an oral intragastric tube every day. The test drug and standard were fed orally for 30 days. The study was completed in overnight fasted rats at the end of 30 days.

\section{Collection of blood}

After the experimental period of 30 days, the animals were sacrificed by cervical dislocation under mild chloroform anesthesia. Blood was collected by decapitation and plasma was separated by centrifugation for 10 min at $3000 \mathrm{rpm}$ and used for the estimation of various biochemical estimations.

\section{High-fat diet and streptozotocin-induced diabetes Animals and diet}

Adult Wistar albino rats weighing about 150-180 g were procured from the animal house of Karpagam Academy of Higher Education, Coimbatore, India. The animals were under standard conditions and were housed four per cage in polypropylene cages with a wire mesh top and a hygienic bed of husk in a specific pathogen-free animal room under controlled conditions of 12-h light and 12-h dark cycle, with a temperature of $24 \pm 2{ }^{\circ} \mathrm{C}$, relative humidity of $50 \pm 10 \%$, and fed with rodent diet and water ad libitum (Table 3 ). The study was approved by Institutional Animal Ethical Committee (IAEC) constituted for the purpose of CPCSEA, Government of India (Approval No. KAHE/IAEC/2018/21-04/009).

\section{Induction of diabetes}

The rats were fed with a high-fat diet (HFD) ad libitum, respectively, for the initial period of 2 weeks. After the 2 weeks of dietary manipulation, the dietary group was injected intraperitoneally (i.p.) with a low dose of STZ (35 mg/ kg b.wt), while the respective control rats were given vehicle citrate buffer $(\mathrm{pH} 4.5)$. Diabetes was 
Table 3 Experimental design for in vivo anti-diabetic study with high-fat diet

\begin{tabular}{ll}
\hline Groups & Treatment \\
\hline Group 1 & Control \\
Group 2 & HFD + STZ-induced diabetic control (35 mg/kg b.wt of STZ) \\
Group 3 & $\begin{array}{l}\text { HFD }+ \text { STZ-induced diabetic rats treated with metformin } \\
(50 \mathrm{mg} / \mathrm{kg} \text { b.wt })\end{array}$ \\
Group 4 & HFD + STZ-induced diabetic rats treated with FNW \\
Group 5 & HFD + STZ-induced diabetic rats treated with LRR \\
Group 6 & HFD + STZ-induced diabetic rats treated with LRS \\
Group 7 & HFD + STZ-induced diabetic rats treated with HAR \\
\hline
\end{tabular}

identified in rats by moderate polydypsia and marked polyuria. After $48 \mathrm{~h}$ of streptozotocin administration, blood glucose levels were estimated in rats following overnight fasting [14].

The animals were weighed and dosed through an oral intragastric tube every day. The test drug and reference standard drugs were fed orally for 3 weeks. The study was completed in overnight fasted rats at the end of 3 weeks.

\section{Collection of blood}

After the experimental period of 3 weeks, the animals were sacrificed by cervical dislocation under mild chloroform anesthesia. Blood was collected by decapitation and plasma was separated by centrifugation for 10 min at $3000 \mathrm{rpm}$ and used for the estimation of various biochemical estimations (glucose, triglycerides, and cholesterol in plasma-Kit Method).

\section{Statistical analysis}

Graphpad Prism-6 software (Graphpad software, Inc., USA) was used for the statistical analysis.

\section{Results}

Total phenolic content

Total phenolic content (TPC) of selected source plants of Jivanti was estimated in different extracts such as methanol, water, and hydro alcohol. TPC was calculated from the calibration curve of gallic acid $\left(R^{2}=0.992\right)$. TPC of various species is presented as Fig. 1 . The highest phenolics were observed for the hydro alcoholic extract of FNW (18.87 mg Eq Ga/g). TPC of LRR showed $3.77,9.07$, and 7.33 for various extracts like methanol, water, and hydro alcohol, respectively. The stem extracts of $L$. reticulata showed higher phenolics for methanol and hydro alcohol extracts compared to that of its root. Phenolic contents of HAR were calculated as 3.10, 5.70, and 4.83 for methanol, water, and hydro alcohol, respectively.

\section{HPTLC profiling}

Comparative chemical profiling of various species was done by HPTLC analysis. HPTLC profiles of sequential $n$ hexane and chloroform extracts were presented in Fig. 2. On visualizing under $254 \mathrm{~nm}, n$-hexane extract showed bands at $R_{\mathrm{f}} 0.26,0.32,044,0.55,0.69$, and 0.73 as common for $L$. reticulata root, $L$. reticulata stem, $H$. ada-kodien root, and F. nodosa. A band at 0.67 was found common for $L$. reticulata and $H$. ada-kodien. Compound with $R_{\mathrm{f}}$ 0.16 was observed in the root and stem of $L$. reticulata. A band at 0.20 was found to be common for $L$. reticulata root and F. nodosa. Chloroform extracts showed a

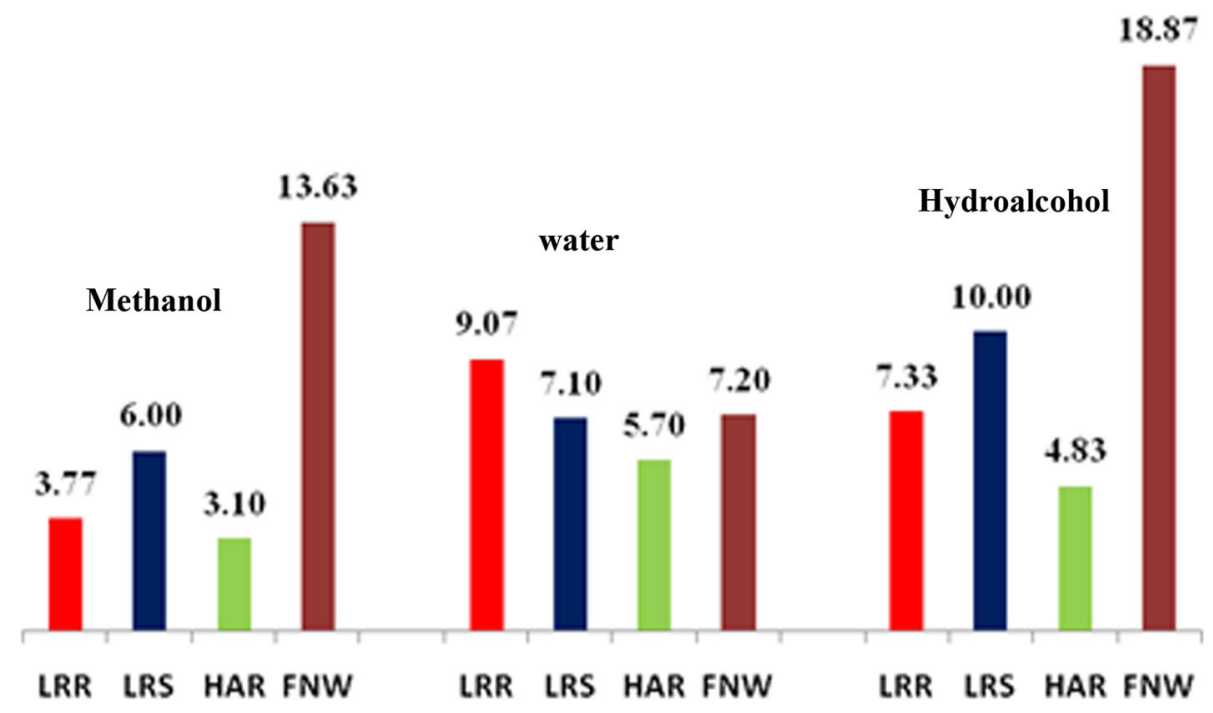

Fig. 1 TPC of various extracts of selected source plants of Jivanti 

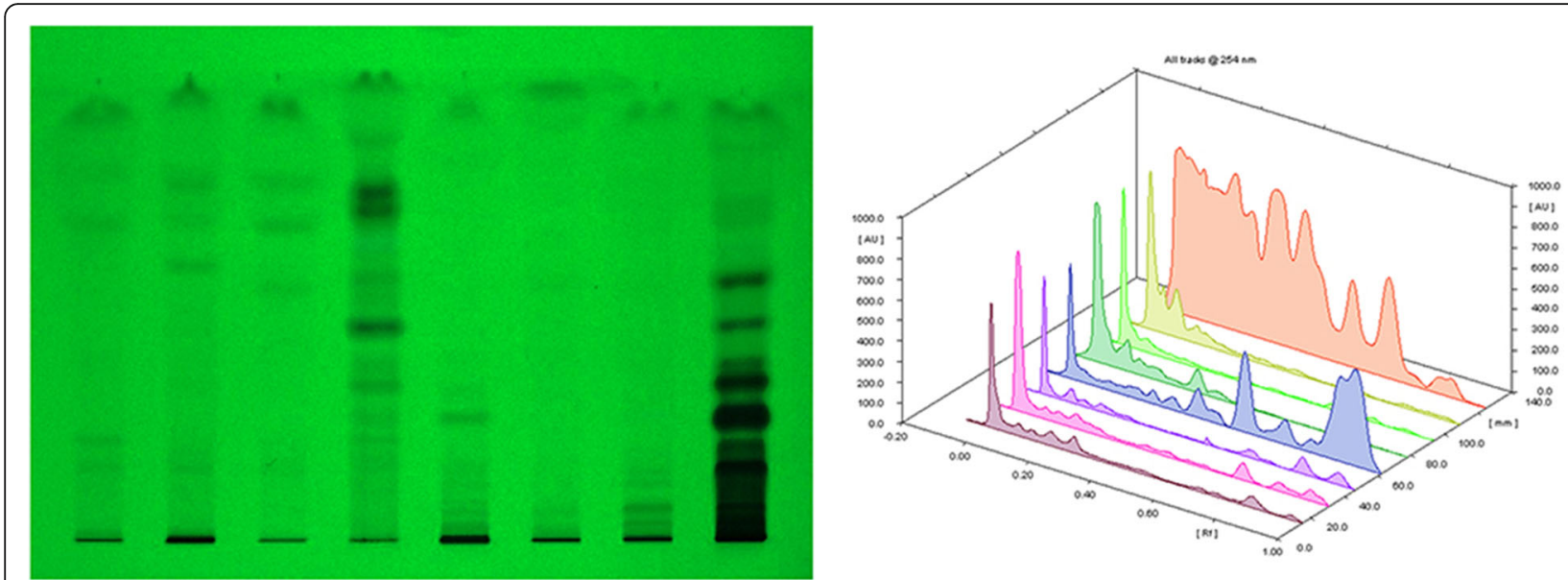

\section{LRR LRS HAR FNW LRR LRS HAR FNW}
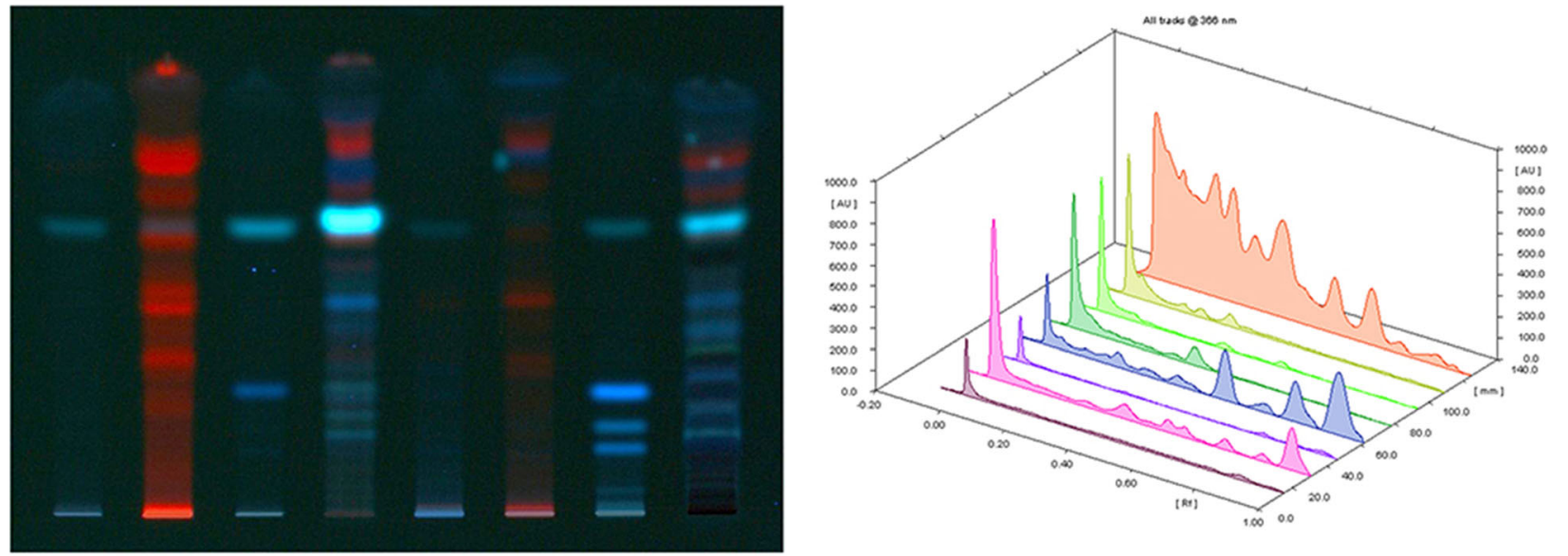

LRR LRS HAR FNW LRR LRS HAR FNW

\section{1-4: n-Hexane extracts; 5-8: chloroform extracts}

Fig. 2 HPTLC profile of sequential n-hexane and chloroform extracts of various Jivanti source plants

common band at 0.04 for the root of $L$. reticulata and $H$. ada-kodien. A compound at 0.08 is common for three extracts except $L$. reticulata stem. $L$. reticulata root and $F$. nodosa showed a common band at 0.26 . Some specific bands were observed for $F$. nodosa at $0.15,0.33,0.45$, and 0.54 . At $366 \mathrm{~nm}, \mathrm{n}$-hexane extract of $L$. reticulata root showed a blue fluorescent band at 0.61 and it is common for all the selected four samples. The stem of $L$. reticulata showed an entirely dissimilar banding pattern with its root. In the case of chloroform extracts, 0.61 (blue) is a common band for all the selected species. Methanol and water extracts also showed different chromatographic patterns (Fig. 3). Only a few compounds are found to be common for methanolic extract.

\section{LC/MS analysis of phenolic fractions}

The phenolic fractions of various samples were subjected to LC/MS analysis for the detailed characterization. LC/MS analysis was done in ESI negative mode. Total ion chromatogram (TIC) was integrated to record all the molecular ion peaks. The molecular ions with different $[\mathrm{M}-\mathrm{H}]$ values were evaluated and further characterization was carried out by MS/MS analysis. On MS/MS analysis, molecular ions were fragmented on collision-induced dissociation (CID). The tentative structure was assigned by comparing mass fragmentation patterns of previously reported values (Table 4).

Flavonoids such as 7,3'-dihydroxy flavones, 3,7-dihydroxy-3', 4' -dimethoxyflavone, and 3,4-dimethoxycinnamic acid were identified from HAR, and LRR showed the presence of protocatechuic acid. Catechin, dihydroxyquercetin, and 2'6'-dihydroxyflavone were detected in FNW [15-22].

\section{Pharmacological studies Anti-inflammatory activity}

Oxidative agents such as reactive oxygen species and reactive nitrogen species are produced in abundant 


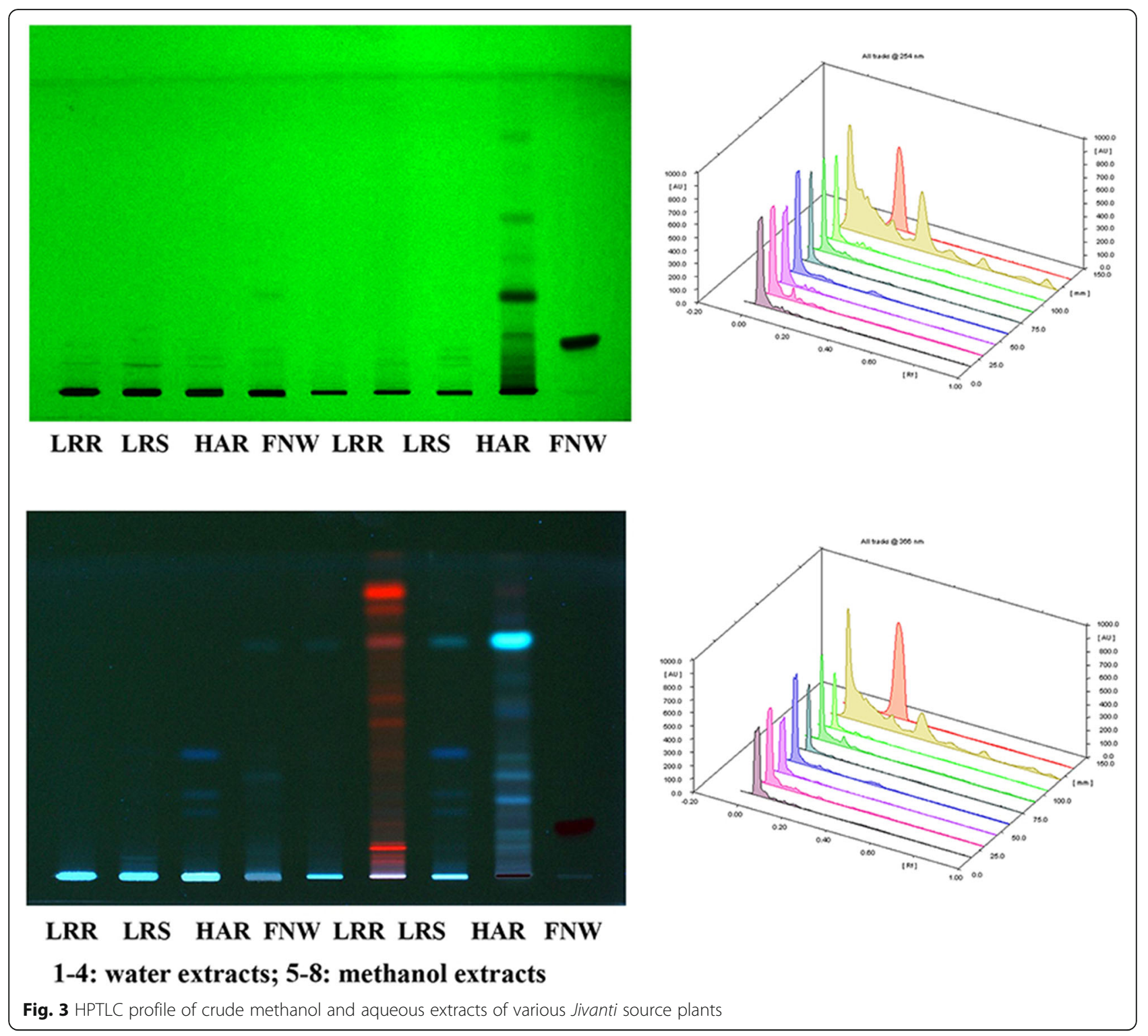

Table 4 LC-MS/MS analysis of the phenolic fraction of selected Jivanti species

\begin{tabular}{|c|c|c|c|c|c|}
\hline Compound & Molecular formula & $m / z[M-H]$ & MS/MS & Present in & Reference \\
\hline Protocatechuic acid & $\mathrm{C}_{7} \mathrm{H}_{6} \mathrm{O}_{4}$ & 153.0103 & $108.02,109.02$ & LRR & [11] \\
\hline 7,3'-Dihydroxy flavones & $\mathrm{C}_{15} \mathrm{H}_{10} \mathrm{O}_{4}$ & 253.1013 & $210.03,165.07,163.0$ & LRS, HAR & {$[12]$} \\
\hline 3,7-Dihydroxy-3', 4'-dimethoxyflavone & $\mathrm{C}_{17} \mathrm{H}_{14} \mathrm{O}_{6}$ & 313.2256 & $295.01,227.17,183.04$ & LRS, HAR & [13] \\
\hline Kaempferol & $\mathrm{C}_{15} \mathrm{H}_{10} \mathrm{O}_{6}$ & 285.0492 & $163,108.02$ & HAR & [14] \\
\hline 3,4-Dimethoxycinnamic acid & $\mathrm{C}_{11} \mathrm{H}_{12} \mathrm{O}_{4}$ & 207.0206 & $163.07,118.99$ & HAR & {$[15]$} \\
\hline Pinocembrine & $\mathrm{C}_{15} \mathrm{H}_{12} \mathrm{O}_{4}$ & 255.1127 & $211.08,184.05,183.08$ & HAR & {$[16]$} \\
\hline Glabranine & $\mathrm{C}_{20} \mathrm{H}_{20} \mathrm{O}_{4}$ & 323.1735 & $178.07,139.05$ & HAR & {$[17]$} \\
\hline Catechin & $\mathrm{C}_{15} \mathrm{H}_{14} \mathrm{O}_{6}$ & 289.1318 & $201.04,158.03$ & FNW & {$[11]$} \\
\hline Dihydroxyquercetin & $\mathrm{C}_{15} \mathrm{H}_{12} \mathrm{O}_{7}$ & 303.1472 & $259.36,199.04,145.02$ & FNW & [18] \\
\hline 2'6'-Dihydroxyflavone & $\mathrm{C}_{15} \mathrm{H}_{10} \mathrm{O}_{4}$ & 253.1014 & $211.04,181.06,147.01,105.03$ & FNW & [19] \\
\hline
\end{tabular}


Table 5 Effect of different extracts on carrageenan-induced paw edema

\begin{tabular}{llllll}
\hline$\%$ Swelling & & & \\
\hline $\begin{array}{l}\text { Group I } \\
\text { Control }\end{array}$ & $\begin{array}{l}\text { Group II } \\
\text { Induced }\end{array}$ & $\begin{array}{l}\text { Group III } \\
\text { FNW }\end{array}$ & $\begin{array}{l}\text { Group IV } \\
\text { LRR }\end{array}$ & $\begin{array}{l}\text { Group V } \\
\text { LRS }\end{array}$ & $\begin{array}{l}\text { Group VI } \\
\text { HAR }\end{array}$ \\
\hline 0 & $100 \pm 0$ & $80.45 \pm 0.009$ & $83.91 \pm 0.06$ & $58.09 \pm 0.95$ & $32.69 \pm 0.37$ \\
\hline
\end{tabular}

The data were represented as mean \pm SD and analyzed by one-way ANOVA followed by Dunnett's multiple comparison tests

quantities during every inflammatory response [23]. The effect of test drug on paw edema induced by carrageenan is presented in Table 5. Different plant extracts such as FNW, LRR, LRS, and HAR at a concentration of $150 \mathrm{mg} / \mathrm{kg}$ showed swelling of $80.45 \%$, 83.91\%, 58.09\%, and $32.69 \%$ respectively when compared to the $100 \%$ swelling of the induced group. $H$. ada-kodien showed comparatively good anti-inflammatory activity among the tested extracts.

\section{Evaluation of anti-diabetic activity by streptozotocin- induced diabetes}

A pool of $\beta$-cell destruction in STZ-induced diabetic rats results into severe insulin deficiency followed by elevation in fasting blood glucose level beyond the normal value. Metformin was used as a standard drug. In the diabetic control rats, glucose, cholesterol, triglycerides, and LDL values were elevated to a high level during the study whereas HDL value was decreased. All the extracts tested showed anti-diabetic activity. HAR and LRS showed significant anti-hyperglycemic activity against STZ-induced diabetes. LRS and HAR showed 35\% and $36 \%$ of decrease in glucose level. Metformin caused $20 \%$ lowering of blood glucose in the same period of the experiment (Table 6).

\section{High-fat diet and streptozotocin-induced diabetes}

The high-fat-fed STZ-treated diabetic rat model was also validated using various extracts (Table 7). The animals treated with LRS and HAR showed a significant decrease in glucose level. Lipid profiling showed that LRS and HAR decreased the elevated cholesterol level.

\section{Discussion}

In Ayurvedic classical texts, the descriptions of medicinal plants are given by synonyms. These synonyms have caused controversy in the identification of plants. It is very important to set methods for identifying the exact source plant for a particular drug among different plants being used under the same name. Phytochemical and pharmacological evaluation of such medicinal plants is the important steps to resolve the controversy. The botanical identity of Jivanti is in a situation of controversy as the various plants such as $L$. reticulata, $H$. adakodien, and F. nodosa are being used as its source plant.

The present study showed that certain chemical constituents are similar for both $L$. reticulata root and H. ada-kodien. HPTLC profiles showed the presence of some specific common compounds which was confirmed by matching $R_{\mathrm{f}}$ values and densitometry scanning. The quantitative estimation of polyphenolics showed that $F$. nodosa contains a high amount of phenolics among the three species studied. The phenolic content of $H$. ada-kodien and $L$. reticulata is in a moderate level and is in agreement with the previous reports [24]. The variation of phenolic content with respect to the nature of extraction solvents such as methanol, water, and hydro alcohol was observed for all the species studied and it might be due to the difference in the polarity of various solvents. The same has been reported for many other species previously $[25,26]$. The literature survey showed that no comparative evaluations of these species are available.

Tandem mass spectroscopic analysis showed the presence of various polyphenolics in the studied Jivanti species. Flavonoids such as 7,3' -dihydroxy flavones, 3,7dihydroxy-3', 4'-dimethoxyflavone, and 3,4-dimethoxycinnamic acid were identified from $H$. ada-kodien, and the root of L. reticulata showed the presence of protocatechuic acid. Catechin, dihydroxyquercetin, and $2^{\prime} 6^{\prime}$ -

Table 6 Anti-diabetic activity in STZ-induced diabetic rats

\begin{tabular}{|c|c|c|c|c|c|c|c|c|}
\hline \multirow[t]{2}{*}{ Groups } & \multicolumn{8}{|l|}{ Parameters } \\
\hline & Glucose & $\mathrm{Hb}$ & HbA1c & Cholesterol & Triglycerides & $\mathrm{HDL}$ & LDL & VLDL \\
\hline Control & $98 \pm 0.5$ & $9 \pm 0.76$ & $5.9 \pm 0.56$ & $198 \pm 1.22$ & $121 \pm 0.89$ & $60 \pm 1.67$ & $113.8 \pm 2.01$ & $24.2 \pm 1.67$ \\
\hline Diabetic control & $126 \pm 1.55$ & $5.2 \pm 0.36$ & $7.9 \pm 0.73$ & $265 \pm 2.06$ & $221 \pm 1.53$ & $31 \pm 1.78$ & $189.8 \pm 1.96$ & $44.2 \pm 0.98$ \\
\hline Standard & $100 \pm 1.57$ & $8.5 \pm 0.51$ & $6.7 \pm 0.98$ & $205 \pm 0.88$ & $110 \pm 0.86$ & $57 \pm 0.97$ & $126 \pm 1.22$ & $22 \pm 1.45$ \\
\hline FNW & $116 \pm 1.42$ & $7.1 \pm 0.2$ & $6.1 \pm 0.8$ & $207 \pm 1.00$ & $119 \pm 0.68$ & $55 \pm 1.23$ & $128.2 \pm 0.98$ & $23.8 \pm 1.29$ \\
\hline LRR & $87 \pm 1.02$ & $6.4 \pm 0.26$ & $6.8 \pm 0.79$ & $205 \pm 1.64$ & $124 \pm 1.25$ & $63 \pm 1.87$ & $117.2 \pm 1.32$ & $24.8 \pm 1.12$ \\
\hline LRS & $81 \pm 1.25$ & $7.1 \pm 0.19$ & $6.3 \pm 0.79$ & $202 \pm 1.89$ & $110 \pm 1.1$ & $60 \pm 0.79$ & $120 \pm 1.01$ & $22 \pm 1.23$ \\
\hline HAR & $82 \pm 0.67$ & $6.1 \pm 0.45$ & $5.1 \pm 1.12$ & $207 \pm 1.68$ & $115 \pm 1.26$ & $61 \pm 1.34$ & $123 \pm 0.67$ & $23 \pm 0.96$ \\
\hline
\end{tabular}

The data were represented as mean \pm SD and analyzed by one-way ANOVA followed by Dunnett's multiple comparison tests 
Table 7 Anti-diabetic activity of HFD with streptozotocin-induced rats

\begin{tabular}{|c|c|c|c|c|c|c|c|c|c|}
\hline \multirow[t]{3}{*}{ Groups } & \multicolumn{9}{|l|}{ Parameters } \\
\hline & \multicolumn{3}{|c|}{ Glucose (mg/dl) } & \multicolumn{3}{|c|}{ Triglycerides (mg/dl) } & \multicolumn{3}{|c|}{ Cholesterol (mg/dl) } \\
\hline & HFD & STZ & Treatment & HFD & STZ & Treatment & HFD & STZ & Treatment \\
\hline Control & $73 \pm 0.76$ & $82 \pm 1.45$ & $85 \pm 0.98$ & $118 \pm 2.01$ & $124 \pm 0.87$ & $120 \pm 1.87$ & $103 \pm 0.98$ & $117 \pm 1.98$ & $107 \pm 1.34$ \\
\hline Diabetic control & $102 \pm 0.89$ & $237 \pm 2.09$ & $249 \pm 0.85$ & $246 \pm 1.67$ & $261 \pm 0.91$ & $282 \pm 1.65$ & $200 \pm 0.76$ & $227 \pm 1.45$ & $251 \pm 1.65$ \\
\hline Standard & $100 \pm 0.87$ & $195 \pm 1.56$ & $115 \pm 1.12$ & $209 \pm 1.45$ & $231 \pm 1.54$ & $163 \pm 1.76$ & $134 \pm 0.97$ & $205 \pm 1.34$ & $116 \pm 1.33$ \\
\hline FNW & $111 \pm 1.34$ & $200 \pm 1.31$ & $142 \pm 1.56$ & $219 \pm 1.76$ & $270 \pm 1.43$ & $139 \pm 1.98$ & $139 \pm 1.02$ & $227 \pm 1.98$ & $123 \pm 1.76$ \\
\hline LRR & $101 \pm 1.23$ & $192 \pm 1.11$ & $138 \pm 1.38$ & $207 \pm 1.45$ & $285 \pm 1.35$ & $146 \pm 1.34$ & $124 \pm 0.89$ & $229 \pm 1.47$ & $120 \pm 1.65$ \\
\hline LRS & $98 \pm 1.11$ & $182 \pm 1.67$ & $112 \pm 0.99$ & $176 \pm 1.47$ & $274 \pm 1.98$ & $155 \pm 1.21$ & $127 \pm 1.12$ & $239 \pm 1.34$ & $124 \pm 1.55$ \\
\hline HAR & $99 \pm 0.96$ & $193 \pm 1.22$ & $104 \pm 1.01$ & $211 \pm 1.32$ & $245 \pm 1.67$ & $175 \pm 1.67$ & $119 \pm 1.43$ & $185 \pm 1.87$ & $111 \pm$ \\
\hline
\end{tabular}

The data were represented as mean \pm SD and analyzed by one-way ANOVA followed by Dunnett's multiple comparison tests

dihydroxyflavone were identified from $F$. nodosa. Most of the compounds identified are biologically active molecules possessing numerous pharmacological properties such as anti-oxidant, anti-diabetic, anti-inflammatory, etc. [27-30].

Anti-inflammatory and anti-diabetic activity of $L$. reticulata has been reported earlier [23]; however, comparative evaluation of the same for various source plants of Jivanti is not yet reported. $H$. ada-kodien showed comparatively good anti-inflammatory activity at a dose level of $100 \mathrm{mg} /$ $\mathrm{kg}$ among the tested species. Type 2 diabetes has become a global health problem. According to the World Health Organization, more than 176 million people are suffering from this disease globally [31]. Both stems of $L$. reticulata and $H$. ada-kodien showed significant anti-diabetic activity. The same was also confirmed with a high-fat diet streptozotocin-induced diabetic model in albino rats.

The results of the present study concluded the possibility of using Holostemma ada-kodien as an alternative source plant for Jivanti in Ayurvedic drug industry as it possessed significant anti-inflammatory and anti-diabetic activity when compared to the genuine source drug, $L$. reticulata.

\section{Conclusion}

Jivanti is a controversial Ayurvedic drug as it has more than one botanical source. Leptadenia reticulata is the genuine source plant of Jivanti according to Ayurvedic Pharmacopeia of India, although Holostemma adakodien and Flickingeria nodosa are also considered as source plants for Jivanti in some parts of the country. In this study, comparative phytochemical and pharmacological evaluation has been carried out to identify alternative source plants for Jivanti. Phytochemical and pharmacological evaluation of various source plants of Jivanti revealed that the root of $\mathrm{H}$. ada-kodien possesses significant anti-inflammatory and anti-diabetic activity exploring the possibility of using the same as a validated substitute of Jivanti.

\section{Abbreviations}

LRR: Leptadenia reticulata root; LRS: Leptadenia reticulata stem; HAR: Holostemma ada-kodien root; FNW: Flickingeria nodosa;

STZ: Streptozotocin; HPTLC: High-performance thin-layer chromatography; LC-MS/MS: Liquid chromatography-mass spectroscopy

\section{Acknowledgements}

The authors are thankful to Dr. Devaki K, Professor and Head, Department of Biochemistry, Karpagam University, Coimbatore, Tamil Nadu, India, for the support in the Ppharmacological study. The authors are also thankful to Dabur India Limited, New Delhi, India, for providing plant materials

\section{Plant authentication}

Plant authentication was done by Plant Systematics and Genetic Resources Division of the institute.

\section{Authors' contributions}

All authors have read and approved the final manuscript. SCT: Designed the study, carried out LC/MS analysis and pharmacological evaluation, and drafted the manuscript. JCK: Carried out the phytochemical analysis. JKU: Participated in the phytochemical analysis. PKM: Collected the plant materials. IB: Participated in study designing and edited the manuscript

\section{Funding}

The entire study was financially supported by the National Medicinal Plants Board, Ministry of AYUSH, Government of India, under R\&D project of central sector scheme (Project \# R\&D/KE-01/2015-16).

Availability of data and materials

All data and material are available upon request.

Ethics approval and consent to participate

The study protocol was approved by the ethical guidelines of CPCSEA after obtaining necessary clearance from the committee (Approval No. KAHE/ IAEC/2018/21-04/008 and KAHE/IAEC/2018/21-04/009).

\section{Consent for publication}

Not applicable

\section{Competing interests}

The authors declare no competing interests.

Received: 8 November 2020 Accepted: 8 February 2021

Published online: 25 February 2021

\section{References}

1. Anjaria JV, Gupta I (1967) Studies on lactogenic property of Leptadenia reticulata and leptaden tablet in goats, sheep, cows and buffaloes. Indian Vet. J. 44:967-974

2. Sivarajan W, Balachandran I (1994) Ayurvedic drugs and their plant sources. Oxford IBH Co.pvt Ltd, pp 195-200 
3. Sharma PC, Yelne MB, Dennis TJ (2001) Database on medicinal plants used in Ayurveda. 1st ed., Vol. 2. CCRAS, Department of ISM and H, Ministry of Health and Family Welfare, Government of India, New Delhi, p 270

4. Raval MA, Mishra SH (2010) Parameters for differentiation of Leptadenia reticulata from substitutes. J. Herbs Spices Med Plants. 16:147-159

5. Mammen D, Daniel M, Sane RT (2011) Pharmacognostic and phytochemical studies on Leptadenia reticulata (retz.) wight \& arn. And Ichnocarpus frutescens for identification of distinguishing biomarkers. Phcog. J. 2:7-12

6. Nema AK, Agarwal A, Kashaw V (2011) Hepatoprotective activity of Leptadenia reticulata stems against carbon tetrachloride-induced hepatotoxicity in rats. Indian J. Pharmacol. 43:254-257

7. Kirtikar KR, Basu BD (1975) Indian medicinal plants, vol 3, 2nd edn. M/S Bishen Singh Mahendrapal, New Delhi, p 1620

8. Madhavan V, Tomar GS, Yoganarasimhan SN, Gurudeva MR (2010) Pharmacognostical studies on Flickingeria nodosa (Dalz.) Seidenf. Stem and pseudobulbs - a botanical source of the Ayurvedic drug Jivanti. Indian J. Nat. Prod. Resour. 1:22-28

9. Singleton VL, Rossi JA (1965) Colorimetry of total phenolics with phosphomolybdic phosphotungstic acid reagents. Am. J. Enol. Vitic. 16: 144-158

10. Sulaiman CT, Gopalakrishnan VK, Balachandran I (2014) Phenolic compounds and antioxidant properties of selected Acacia species. J. Biol. Act. Prod. Nat. 4:316-324

11. Sulaiman CT, Thushar KV, George S, Balachandran I (2014) Phenolic characterisation of selected Salacia species using LC-ESI-MS/MS analysis. Nat. Prod. Res. 28:1021-1024

12. Sulaiman $C T$, Ramesh PR, Mahesh K, Madhu KM, Anandan EM, Praveen M, Balachandran I (2020) Futur J Pharm Sci 6:40. https://doi.org/10.1186/s43 094-020-00062-w

13. Adeyemi O, Okpo SO, Ogunti O (2002) Analgesic and anti-inflammatory effects of the aqueous extract of leaves of Persea americana Mill (Lauraceae). Fitoterapia 73:375-380

14. Aslan M, Orhan DD, Orhan N, Sezik E, Yesilada E (2007) In vivo antidiabetic and antioxidant potential of Helichrysum plicatum ssp. plicatum capitulums in streptozotocin induced diabetic rats. J Ethnopharmacol. 109:54-59

15. Luiz L, Vilegas SW, Dokkedal AL (2013) Characterization of flavonoids and phenolic acids in Myrcia bella Cambess. Using FIA-ESI-IT-MSn and HPLCPAD-ESI-IT-MS combined with NMR. Molecules. 18:8402-8416

16. Simirgiotis MJ, Benites J, Areche C, Sepúlveda B (2015) Antioxidant capacities and analysis of phenolic compounds in three endemic Nolana species by HPLC-PDA-ESI-MS. Molecules. 20:11490-11507

17. Chen Y, Yu H, Wu H, Pan Y, Wang K, Jin Y, Zhang C (2015) Characterization and quantification by LC-MS/MS of the chemical components of the heating products of the flavonoids extract in Pollen Typhae for transformation rule exploration. Molecules. 20:18352-18366

18. Nagy K, Redeuil K, Williamson G, Rezzi S, Dionisi F, Longet K, Destaillats F, Renouf M (2011) First identification of dimethoxycinnamic acids in human plasma after coffee intake by liquid chromatography-mass spectrometry. J Chromatogr A. 1218:491-497

19. Seraglio SKT, Valese AC, Daguer H, Bergamo G, Azevedo MS, Gonzaga LV, Fett R, Costa ACO (2016) Development and validation of a LC-ESIMS/MS method for the determination of phenolic compounds in honeydew honeys with the diluted-and-shoot approach. Food Res. Inter. 87:60-67

20. Ismail NA, Jusoh SA (2017) Molecular docking and molecular dynamics simulation studies to predict flavonoid binding on the surface of DENV2 $\mathrm{E}$ protein. Interdiscip Sci. 9:499-511

21. Abad-García B, Garmón-Lobato S, Berrueta LA, Gallo B, Vicente FA (2009) Fragmentation study of dihydroquercetin using triple quadrupole mass spectrometry and its application for identification of dihydroflavonols in citrus juices. Rapid Commun Mass Spectrom. 23:2785-2792

22. Pandey R P, Parajuli P, Pokhrel A.R, Sohng J K (2018) Biosynthesis of novel 7,8-dihydroxyflavone glycoside derivatives and in silico study of their effects on BACE1 inhibition, Biotech \& applied Biochem. 65: 128-137.

23. Mittal M, Siddiqui MR, Tran K, Reddy SP, Malik AB (2014) Reactive oxygen species in inflammation and tissue injury. Antioxid Redox Signal. 20:1126-1167

24. Mohanty SK, Swamy MK, Sinniah UR, Anuradha M (2017) Leptadenia reticulata (Retz.) Wight \& Arn. (Jivanti): botanical, agronomical, phytochemical, pharmacological, and biotechnological aspects. Molecules. 22:1019

25. Fernandes A, Fernandes I, Cruz L, Mateus N, Cabral M, Freitas V (2009) Antioxidant and Biological Properties of Bioactive Phenolic Compounds from Quercus suber L. J. Agric. Food Chem. 57:11154-11160

26. Anwar F, Przybylski R (2012) Effect of solvents extraction on total phenolics and antioxidant activity of extracts from flaxseed (Linum usitatissimum L.). Acta Sci Pol Technol Aliment. 11:293-301

27. Kchaou W, Abbès F, Blecker C, Attia H, Besbes S (2013) Effects of extraction solvents on phenolic contents and antioxidant activities of Tunisian date varieties (Phoenix dactylifera L.). Industrial Crops and Products. 45:262-269

28. Pereira DM, Valentão P, Pereira JA, Andrade PB (2009) Phenolics: From Chemistry to Biology. Molecules. 14:2202-2211

29. Fukumoto LR, Mazza G (2000) Assessing antioxidant and prooxidant activities of phenolic compounds. J. Agric. Food Chem. 48:3597-3604

30. Muthusamy VS, Anand S, Sangeetha KN, Sujatha S, Lakshmi BABS (2008) Tannins present in Cichorium intybus enhance glucose uptake and inhibit adipogenesis in 3T3-L1 adipocytes through PTP1B inhibition. Chem. Biol. Interact. 174:69-78

31. Jaiswal YS, Tatke PA, Gabhe SY, Vaidya AB (2017) Antidiabetic activity of extracts of Anacardium occidentale Linn. leaves on n-streptozotocin diabetic rats. J. Tradit. Med. Complement. 7:421-427

\section{Publisher's Note}

Springer Nature remains neutral with regard to jurisdictional claims in published maps and institutional affiliations.

\section{Submit your manuscript to a SpringerOpen ${ }^{\circ}$ journal and benefit from:}

- Convenient online submission

- Rigorous peer review

- Open access: articles freely available online

High visibility within the field

- Retaining the copyright to your article

Submit your next manuscript at $>$ springeropen.com 